\title{
Whole genome sequencing and comparative genomic analyses of two Vibrio cholerae 0139 Bengal-specific Podoviruses to other N4-like phages reveal extensive genetic diversity
}

Derrick E Fouts' ${ }^{1}$, Jochen Klumpp ${ }^{2 *}$, Kimberly A Bishop-Lilly ${ }^{3,4}$, Mathumathi Rajavel ${ }^{5}$, Kristin M Willner ${ }^{3,4}$, Amy Butani ${ }^{3,4}$, Matthew Henry ${ }^{3,4}$, Biswajit Biswas ${ }^{3,4}$, Manrong Li $i^{6}$, M John Albert ${ }^{7}$, Martin J Loessner ${ }^{2}$, Richard Calendar ${ }^{8}$ and Shanmuga Sozhamannan ${ }^{3,4,9}$

\begin{abstract}
Background: Vibrio cholerae $\mathrm{O} 139$ Bengal is the only serogroup other than $\mathrm{O} 1$ implicated in cholera epidemics. We describe the isolation and characterization of an O139 serogroup-specific phage, VB_VchP_VchO139-I ( $\$$ VchO139-I) that has similar host range and virion morphology as phage VB_VchP_JA1 ( $\phi J A 1)$ described previously. We aimed at a complete molecular characterization of both phages and elucidation of their genetic and structural differences and assessment of their genetic relatedness to the N4-like phage group.

Methods: Host-range analysis and plaque morphology screening were done for both $\phi J A 1$ and $\phi V$ chO139-I. Both phage genomes were sequenced by a 454 and Sanger hybrid approach. Genomes were annotated and protein homologies were determined by Blast and HHPred. Restriction profiles, PFGE patterns and data on the physical genome structure were acquired and phylogenetic analyses were performed.

Results: The host specificity of $\phi J A 1$ has been attributed to the unique capsular O-antigen produced by 0139 strains. Plaque morphologies of the two phages were different; $\phi V$ chO139-I produced a larger halo around the plaques than $\phi J A 1$. Restriction profiles of $\phi J A 1$ and $\phi V$ chO139-I genomes were also different. The genomes of $\phi J A 1$ and $\phi V$ chO139-I consisted of linear double-stranded DNA of 71,252 and 70,938 base pairs. The presence of direct terminal repeats of around 1974 base pairs was demonstrated. Whole genome comparison revealed single nucleotide polymorphisms, small insertions/deletions and differences in gene content. Both genomes had 79 predicted protein encoding sequences, of which only 59 were identical between the two closely related phages. They also encoded one tRNA-Arg gene, an intein within the large terminase gene, and four homing endonuclease genes. Whole genome phylogenetic analyses of $\phi J A 1$ and $\phi V$ chO139-I against other sequenced N4-like phages delineate three novel subgroups or clades within this phage family.
\end{abstract}

Conclusions: The closely related phages feature significant genetic differences, in spite of being morphologically identical. The phage morphology, genetic organization, genomic content and large terminase protein based phylogeny support the placement of these two phages in the Podoviridae family, more specifically within the N4-like phage group. The physical genome structure of $\phi J A 1$ could be demonstrated experimentally. Our data pave the way for potential use of $\phi J A 1$ and $\phi V$ chO139-I in Vibrio cholerae typing and control.

Keywords: Vibrio cholerae O139, N4-like virus, Genome comparison, Terminal repeats, Intein, Phylogenetic relationship

\footnotetext{
* Correspondence: jklumpp@ethz.ch

${ }^{2}$ Institute of Food, Nutrition and Health, ETH Zurich, Schmelzbergstrasse 7 ,

8092, Zurich, Switzerland

Full list of author information is available at the end of the article
} 


\section{Background}

Cholera is an acute diarrheal disease caused by ingestion of food or water contaminated with the Gram-negative bacterium Vibrio cholerae. These organisms reside and survive within environmental reservoirs during interepidemic periods and cause seasonal outbreaks in cholera endemic countries. Cholera is a major concern in parts of the world lacking adequate sanitary infrastructure, especially during mass migration of populations due to human driven or natural disasters, as was evident during the 2010 cholera epidemics in Haiti [1-3]. V. cholerae has a short incubation period and produces an enterotoxin that causes a copious, painless, watery diarrhea that can quickly lead to severe dehydration and death, if treatment is not promptly administered. Up to $80 \%$ of cases can be successfully treated with oral rehydration salts $[4,5]$. Since 2000, the incidence of cholera has increased steadily, culminating in 589,854 reported cases from 58 countries worldwide, including 7816 deaths in 2011, with a case-fatality rate (CFR) of $1.3 \%$ $[4,5]$. However, according to the World Health Organization, an estimated 3-5 million cholera cases and 100,000-120,000 deaths occur every year, underscoring the severity of this disease $[4,5]$.

More than 200 serogroups of $V$. cholerae are known [6]. However, all seven pandemics in the recorded history of cholera have been caused by $V$. cholerae strains of the $\mathrm{O} 1$ serogroup. The $6^{\text {th }}$ and $7^{\text {th }}$ pandemic $\mathrm{O} 1$ strains belong to the Classical and El Tor biotypes, respectively [7]. V. cholerae O139 Bengal, a novel pathogen that emerged in late 1992, has remained endemic in South Asia [8]. There is overwhelming genetic evidence supporting the hypothesis that the O139 serogroup emerged from an O1 El Tor strain by horizontal transfer of the O-antigen gene cluster $[9,10]$. The evolution of $V$. cholerae, as a pathogen, is fairly well understood. Two major virulence factors; CTX (encoding the cholera toxin) and TcpA (encoding the toxin coregulated pilus) and the master regulatory factor, ToxT have been extensively characterized $[11,12]$. In a landmark study, the genes encoding cholera toxin, $\operatorname{ctx} \mathrm{AB}$, were shown to be carried on, and horizontally transferred by, a filamentous phage, $\phi$ CTX [13].

Successful epidemiological surveillance and public health intervention of disease outbreaks (such as containment of the disease spread and administration of medical countermeasures) depend on rapid, accurate and inexpensive identification of the etiological agent. Besides the potential therapeutic use of phages, the specificity of phage-bacterial interaction has been exploited for accurate identification of bacteria. Phage-typing schemes have been in use for identification of many bacterial pathogens with high specificity, the most notable being Salmonella, Mycobacterium and Listeria [14-16].
Phage-typing schemes have also been in use for sub typing Classical and El Tor $V$. cholerae strains. These schemes have been periodically updated with new phages to address the changing genetic and epidemiological profiles of $V$. cholerae strains during yearly epidemics $[17,18]$. During the V. cholerae O139 outbreaks of 1992 in the Indian subcontinent, a phage designated as $\phi J A 1$ belonging to the family Podoviridae, which specifically infects O139 strains, was isolated in Dhaka [19]. Several additional phages specific for this new pathogen were subsequently isolated, and a new phage typing scheme for V. cholerae O139 has been put forth [20].

The $V$. cholerae O139-specific $\phi J \mathrm{~A} 1$ has been further characterized. It was hypothesized that the O139 Oantigen is the phage receptor since mutants lacking the $\mathrm{O}$-antigen were found to be phage resistant $[9,19]$. Furthermore, a phage-encoded lyase enzyme was shown to degrade the $\mathrm{O} 139$ polysaccharide [21,22]. However, neither has the genome sequence of this phage been determined nor has the gene encoding the lyase enzyme been identified yet.

Here we present the genetic characterization of another $V$. cholerae O139 Bengal-specific phage, \$VchO139-I, isolated in 1999 and compare it to фJA1 isolated in 1992. $\phi$ VchO139-I is a lytic, double-stranded DNA phage, similar but not identical to $\phi J A 1$ [19]. We also present the genomic sequences of phages $\phi J A 1$ and $\phi$ VchO139-I and compare their genetic organization and genomic content to seventeen other currently available phages of the N4like group.

\section{Results and discussion}

\section{Isolation and characterization of $V$. cholerae phage} $\phi$ Vch0139-I

A phage that infects $V$. cholerae O139 Bengal, designated as $\phi V$ chO139-I, was isolated in 1999 from the sewage effluent of the International Centre for Diarrheal Disease Research, Bangladesh (ICDDR,B), hospital in Dhaka. Upon transmission electron microscopic analysis, $\phi$ VchO193-I was found to have similar morphology to a $V$. cholerae phage described earlier, namely $\phi J A 1$ [19]. Both phages featured isometric heads and short noncontractile tails with 6 short fibers, clearly placing them in the Podoviridae family of the order Caudovirales $[23,24]$. $\phi \mathrm{JA} 1$ and $\phi \mathrm{VchO} 139-\mathrm{I}$ have a capsid diameter of $\sim 68.7 \mathrm{~nm}$ and $\sim 64.8 \mathrm{~nm}$, respectively (Figure 1 ).

$\phi J A 1$ was isolated from the same location seven years prior to the isolation of $\phi$ VchO139-I. Also, $\phi$ VchO139-I has the same host range as $\phi J A 1$. Like $\phi J A 1, \phi V c h O 139-$ I infected all tested strains of $V$. cholerae serogroup O139, but failed to infect any other serogroup strain (serogroup O1-O206) (Additional file 1: Figure S1) or O139 Bengal acapsular mutants (data not shown). фJA1 is known to produce a characteristic halo around the 


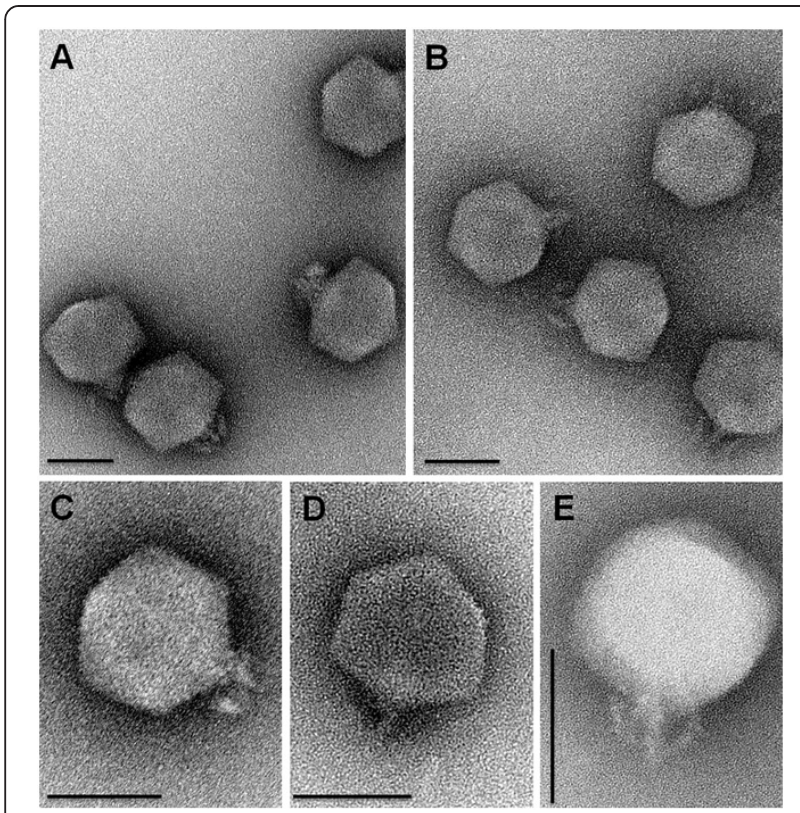

Figure 1 Transmission electron micrographs of phages $\phi \mathrm{JA} 1$ and $\boldsymbol{\phi V}$ ch0139-I. Plates A-D show images of phage particles negatively stained with $2 \%$ uranyl acetate and plate $E$ shows an image of a phage particle negatively stained with $2 \%$

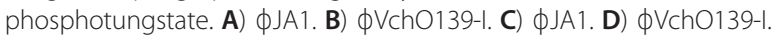
E) $\phi V$ chO139-I. Scale bar represents $100 \mathrm{~nm}$. Podoviridae morphology of $\phi J A 1$ and $\phi V$ chO139-I particles is evident. plaque postulated to be due to the degradation of $\mathrm{O} 139$ capsular polysaccharide by a polysaccharide lyase secreted from phage-infected and lysed bacteria [21,22].

Although the virion morphologies of $\phi J A 1$ and $\phi$ VchO139-I were similar, their plaque morphologies were slightly different. Consistently, a larger halo was seen around all the plaques produced by $\phi$ VchO139-I compared with that of $\phi J A 1$ in $2 x Y T$ soft agar plates (Figure 2). This difference could be attributed to the genetic differences between the two phages leading to variance in the expression level or the amount or the activity of a secreted lyase. Single-step growth experiments indicated that neither the time of lysis nor the burst size was different for $\phi J A 1$ and $\phi V \mathrm{ChO} 139-\mathrm{I}$. Both phages had a burst size of about 150 and lysis time of about $60 \mathrm{~min}$ in $\mathrm{LB}$ at $37^{\circ} \mathrm{C}$ (data not shown).

Based on electron micrographic DNA length measurements, the genome size of $\phi \mathrm{VchO} 139-\mathrm{I}$ was estimated to be $69.9 \mathrm{~kb}$ (data not shown). PFGE estimate indicated a genome size of approximately $72 \mathrm{~kb}$ for both phages $\phi J A 1$ and $\phi$ VchO139-I (Additional file 1: Figure S2A). Restriction fragment length polymorphism (RFLP) patterns of the genomes of $\phi J A 1$ and $\phi$ VchO139-I with several enzymes were different (HpaII, ClaI, XmnI) whereas with some other enzymes (EcoRI and HindIII) they were identical (Additional file 1: Figure S2B).

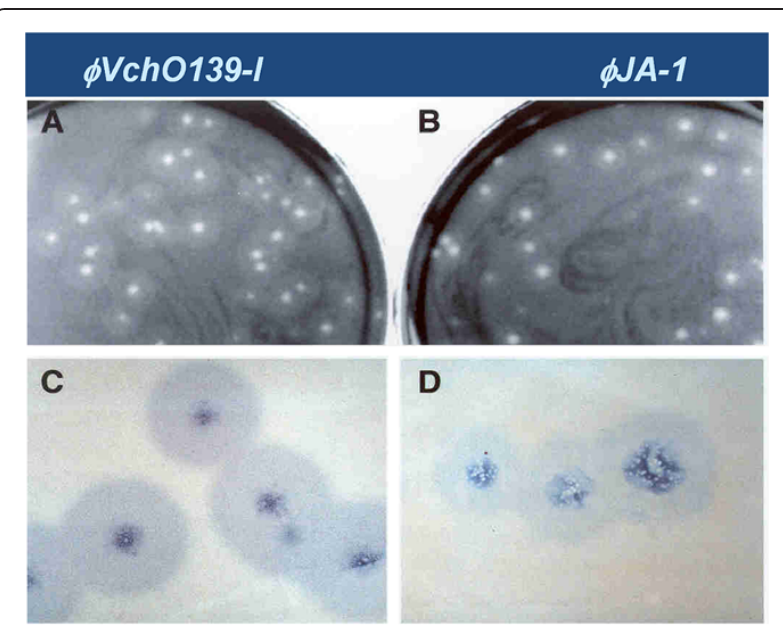

Figure 2 Plaque morphology of phages $\phi J A 1$ and $\phi$ Vch0139-I. Bacterial lawns of $V$. cholerae O139 Bengal strain Al1834 prepared on 2XYT bottom and top agar show differing plaque morphologies of phages $\phi J A 1$ and $\phi V$ chO139-I. A) \$VchO139-I; B) фJA1; C) \$VchO139-I closeup view of plaques; D) $\phi J A 1$ close-up view of plaques.

\section{Identification of virion structural proteins}

The virion protein profiles of the two phages were examined by gradient SDS-PAGE (Figure 3). Both phages exhibited indistinguishable protein profiles. The identity of peptide fragments from SDS-gel bands was elucidated by peptide mass fingerprinting. A corresponding coding

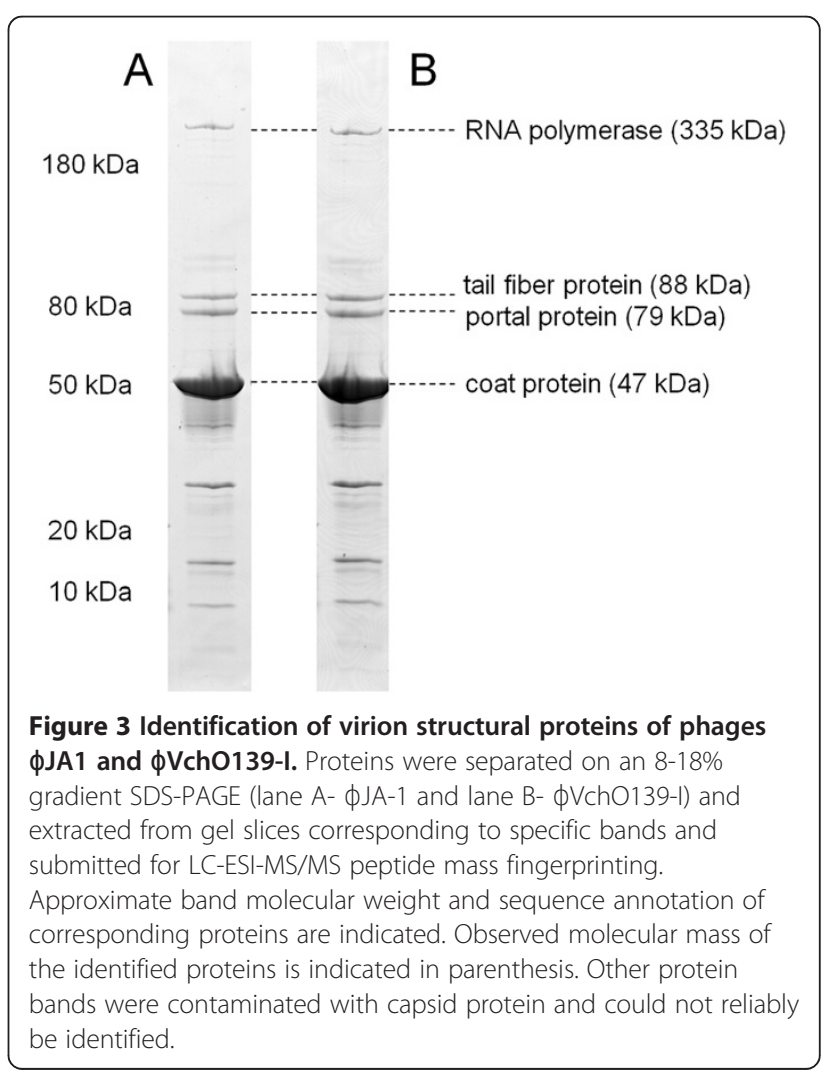


sequence could be assigned to four of the eight prominent bands (Figure 3) by using DNA sequence annotation, which was generated subsequently (see below). The largest protein, (encoded by a 9,069 bp gene, JA1_0053 and VCO139_0054 with a predicted mass of about $335 \mathrm{kDa}$ ) corresponds to a virion-encapsulated RNA polymerase protein (vRNAP). The presence of this protein is a hallmark of the N4-like phage family [25]. The discrepancy seen between the predicted and observed masses of vRNAP protein could indicate the limitation of size estimation by SDS-PAGE in this size range. The most prominent band was identified as the major capsid protein (encoded by JA1_0059 and VCO139_0060) with a predicted and estimated mass of $47 \mathrm{kDa}$. The portal protein (encoded by JA_0062 and VCO139_0063) with a predicted and an estimated mass of $79 \mathrm{kDa}$ and a putative phage minor structural protein (encoded by JA_0065 and VCO139_0066) with an estimated and predicted mass of $87 \mathrm{kDa}$ were identified in both phages. The identification of additional bands was obscured by the presence of the heavily overrepresented major capsid protein in bands of lower molecular mass, probably due to trapping effects or degradation processes. Similar difficulties have been observed in other peptide mass fingerprinting experiments in different phages [26].

Despite the fact that phages $\phi J \mathrm{~A} 1$ and $\phi$ VchO139-I exhibit differences in halo size of their plaques, we did not observe any difference in the relative concentration of any protein in the gel. Based on all these structural characteristics, $\phi J A 1$ and $\phi$ VchO139-I appeared to be very similar phages with minor differences.

\section{Genome sequencing of $\phi \mathrm{JA} 1$ and $\phi \mathrm{VchO} 139 \mathrm{I}$}

In order to decipher the genetic differences between the two phages, we carried out whole genome sequencing of the two phages. An initial draft genome of $\phi J A 1$ and $\phi$ VchO139-I was obtained by Sanger-based whole genome shotgun sequencing with finishing reactions performed for $\phi \mathrm{JA} 1$. The Sanger assembled single contigs of $\phi J A 1$ and $\phi V \mathrm{chO} 139$-I genomes were 69,755 and 68,268 bps in size respectively. We reasoned that the genome was incomplete at this stage because of the discrepancy we observed between the genome sizes of the assembled genomes and the PFGE size estimate $(\sim 72 \mathrm{~kb})$ as well as restriction fragments not accounted for by the assembly. Since it is possible that some of the clones were toxic to E. coli and hence were excluded, a cloning-independent NextGen sequencing approach was taken to complete the DNA sequencing of these genomes. To accomplish this, an additional 502,102 ( $\phi J A 1)$ and 507,297 ( $\phi$ VchO139-I) 454 pyrosequencing reads were generated. De novo assembly of a subset of 15,000 Roche/454 reads each resulted in single contigs of 69,751 bp and 69,354 bp for $\phi J A 1$ and $\phi$ VchO139-I respectively. All 454 and for $\phi J A 1$ additional Sanger reads were mapped back to these contigs. Regions of low coverage were confirmed by Sanger sequencing.

\section{Determination of the structure and linearity of $\phi J A 1$ and $\phi$ Vch0139-I genomic ends}

Because the $\phi \mathrm{JA} 1$ genome sequence had a better quality assembly, having had more successful finishing reactions and fewer sequence ambiguities, it was used to determine the sequence of the genome ends. The resultant mapping assembly revealed a pile-up of 454 reads spanning the terminal 1,974 base pairs at the $3^{\prime}$ end of the assembly with twice the sequence depth of the remainder of the genome. This suggested that this specific sequence is present twice in the phage genome (Additional file 1: Figure S3), which could explain the size discrepancy. It is well known that N4-like phages have terminal repeats, but they are usually not identical.

Analysis of terminal restriction enzyme fragments and primer walks were used to partially determine the structure of the $\phi J A 1$ genomic ends. We were unable to clone the terminal restriction fragments of the genome in order to obtain sequences corresponding to the putative genomic ends that could be mapped onto the assembly. Bal31 nuclease pre-treatment was used to help identify the true physical ends of the genome as described previously [26]; however, no progressive shortening of any restriction fragment was observed, indicating that the $\phi J A 1$ and $\phi$ VchO139-I genomic ends are inaccessible to Bal31 enzyme. A pre-digestion with proteinase $\mathrm{K}$ also did not improve Bal31 accessibility to the ends, indicating the absence of a covalently bound terminal protein (data not shown). It is possible that inter or intra molecular circularization of the genomes prevent Bal31 entry. Hence, at present, the reason for Bal31 resistance of the phage genomic termini is unclear.

Oligonucleotide primers were designed to sequence off the ends of the \$JA1 genome. The 3' genomic end was predicted to be contained within a $7.8 \mathrm{~kb}$ Sall fragment (see Figure 4 JA-1 map for location of restriction site); therefore, the gel-purified Sal fragment was used as template for sequencing reactions. Primers designed to read off the 3' end of the genome exhibited a detectable drop in signal intensity, indicating the likely $3^{\prime}$ genome end had been reached (data not shown). The 3 ' end terminated with a 12 nucleotide motif (GATAGGGGATAG), an inverted repeat of 'GATAGG' that is similar to motifs found in other N4-like phages, such as EaS6 [27]. Sequencing off of the predicted $5^{\prime}$ end, using the $5^{\prime} 1.6 \mathrm{~kb} \mathrm{NruI}$ fragment (Figure 4), produced the same 12-nucleotide motif across the junction between the unique sequence and the repeat region at the $5^{\prime}$ end. However, further sequencing using outward primers did not result in any visible loss in signal intensity that would indicate that the 


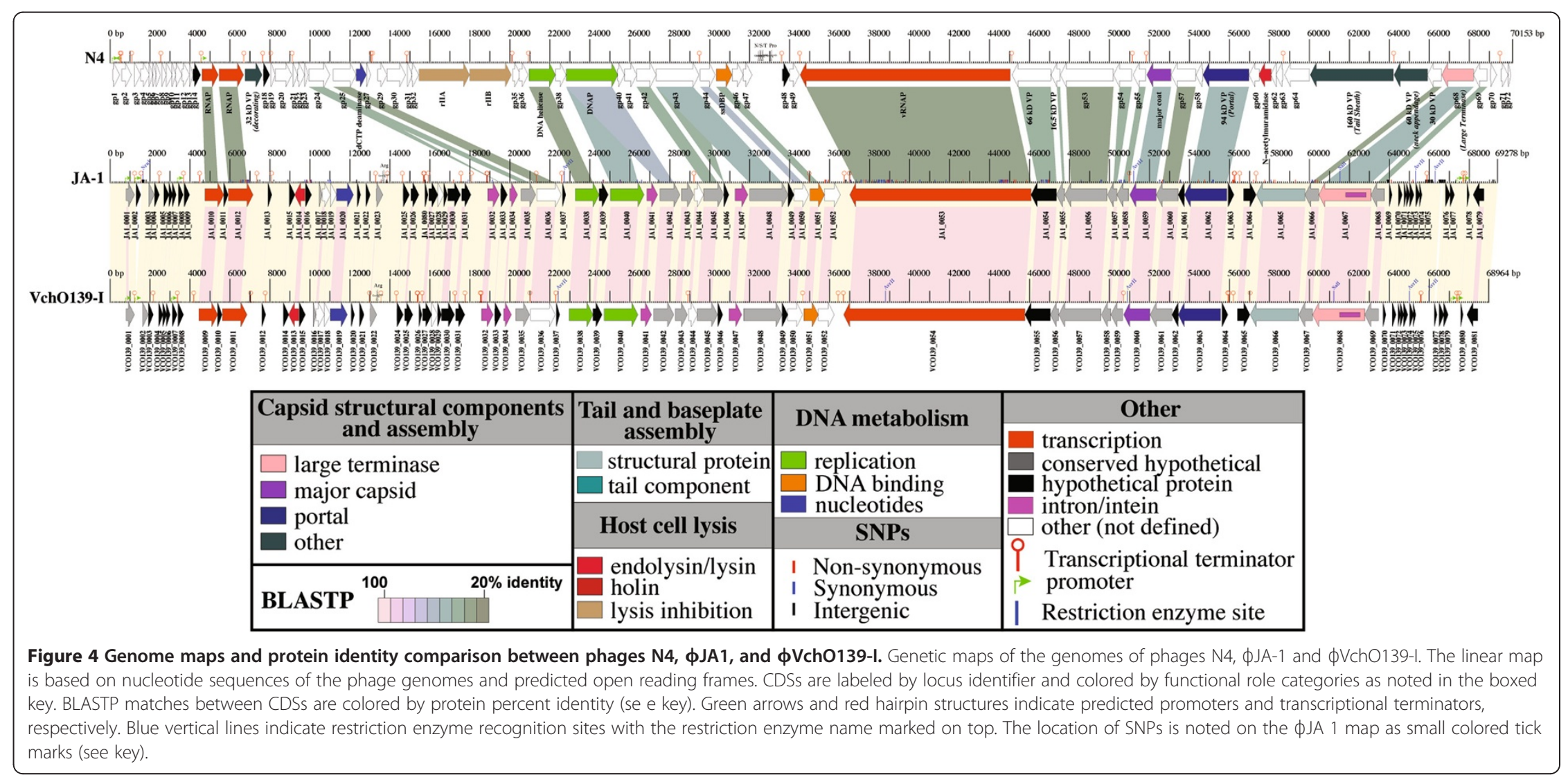


terminus had been reached. These results indicated possible contamination of the template with molecules having other topologies such as intra molecular circles or inter molecular dimers of phage DNA. Because of this result, the genome sequence of $\phi J A 1$ is represented with the repeat at only the 3 ' end, yielding a total non-redundant genome size of $69,278 \mathrm{bps}$. The length of the repeat was estimated from the coordinates of the 3 ' pile-up to be at least $1,974 \mathrm{bps}$; therefore, the predicted terminally redundant genome length of $\phi J A 1$ is estimated to be about 71,252 bps. $\phi$ VchO139-I has similar repeats at the ends of the genome and was unresolved at the $5^{\prime}$ terminus, with genome sizes of the non-redundant and terminally redundant genome estimated to be 68,964 bps and about 70,938 bps respectively. These results highlight the inherent difficulty associated with sequencing repeat regions (in this case about 2,000 bps) of more than the average read lengths of the sequencing platforms used in this study. The average Sanger read lengths are about $900 \mathrm{bps}$ and that of 454 around $400-600$ bps. It is possible to overcome this problem either by combining paired-end read data or generating read data from platforms such as PacBio that currently produces mean average read lengths of around $4.5 \mathrm{~kb}$ [28].

To determine whether the $\phi J A 1$ genome is linear or circularly permuted and whether the ends are fixed or variable, restriction enzyme analyses were performed. Restriction digestion of $\phi J A 1$ DNA produced two distinct fragments when cut with enzymes that have single recognition sites (SalI, PauI and NheI) and three distinct fragments when cut with enzymes that have two sites such as ClaI (data not shown). $\phi$ VchO139-I DNA was cut into two distinct fragments when single cutters ClaI and PauI were used (data not shown). Both фJA1 and $\phi$ VchO139-I DNAs produced three fragments upon double digestion with enzymes that have a unique restriction site (e.g., XhoI-AhdI, XhoI-SalI and XhoI-SphI) (Additional file 1: Figure S2A). These findings clearly indicate a fixed linear genome structure without circular permutation [26]. Possible cohesive genome ends (cos) were examined by heating one half of ClaI, Van91I and OliI restriction digests for $10 \mathrm{~min}$ at $75^{\circ} \mathrm{C}$ prior to electrophoresis. This heating step did not change the fragment pattern, compared to the unheated control, thus excluding the presence of cohesive genomic ends (data not shown) [29]. This finding is consistent with the placement of these phages in N4-like phage group (see below) in that N4- like phages are not known to have $\cos$ sites [30].

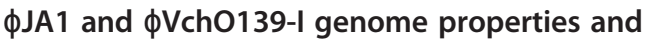 polymorphisms}

Despite having been isolated seven years apart, $\phi J A 1$ and $\phi$ VchO139-I have very similar genetic organization and genome sequences. The non-redundant genomes of $\phi J A 1$ and $\phi$ VchO139-I were found to be 69,278 bps and 68,964 bps in length, respectively with an identical $\mathrm{G}+\mathrm{C}$ $\mathrm{mol} \%$ of $34.6 \%$, which differs considerably from the $\mathrm{G}+$ $\mathrm{C}$ mol\% of the genome of the host $V$. cholerae, which averages $\sim 47.6 \%$ per strain. Direct pairwise comparison of their genomes at the nucleotide level revealed that they are $99 \%$ identical across $99 \%$ of the length, using NCBI Megablast. The differences were due to a total of 298 single nucleotide polymorphisms (SNPs) and two small insertions/deletions (JA1_0002 and VCO139_0077 have no ortholog in the other genome, Figure 4). The absence of these CDSs in the other genome was confirmed by BLASTN analysis. Of these SNPs, 96 were intergenic, 139 SNPs were synonymous, and 63 resulted in nonsynonymous amino acid coding changes in 19 proteins (Figure 4, Additional file 1: Table S1). Additionally, there were 79 predicted protein-coding sequences identified in the genomes of $\phi J A 1$ and $\phi$ VchO139-I, of which 59 are identical between the two phages. Of these, 53 were shown to be $100 \%$ identical at the nucleotide level (Additional file 1: Table S1). Both $\phi J A 1$ and $\phi$ VchO139-I encode a single tRNA-Arg gene between JA1_0023 and JA1_0025 in $\phi J A 1$ and VCO139_0022 and VCO139_0024 in $\phi$ VchO139-I and an intein within the large terminase gene.

\section{Comparison of $\phi \mathrm{JA} 1$ and $\phi \mathrm{VchO139-I}$ with N4}

Top BLASTP matches in the NCBI nr database revealed relatedness to $E$. coli phage N4-like phages. Comparison with $E$. coli phage N4 revealed $22 \mathrm{~N} 4$ proteins with BLASTP matches to $\phi J A 1$ and considerable synteny (Figure 4). These matches include functions involved in head morphogenesis (i.e., large terminase, portal, and major coat proteins), transcription (i.e., both N4 RNA polymerase proteins), and replication (i.e., DNA helicase, ssDNA-binding protein (DBP) and DNA polymerase proteins). The presence of the very large (around 335 $\mathrm{KDa}$ ) virion-encapsulated RNA polymerase (vRNAP) is a hallmark of the N4-like phages as well as the heterodimeric RNA polymerase used in middle mode transcription [31]. Like bacteriophage T4, N4 has homologs of the 'rapid-lysis' genes, $r I I A$ and $r I I B$ [32,33]; however, both $\phi J A 1$ and $\phi$ VchO139-I lack homologs of these genes. Likewise, homologs of the N4 major tail protein (gp65), neck appendage (gp66), and virion decorating (gp17) proteins appear to be missing from $\phi J A 1$ and $\phi$ VchO139-I as well as an N-acetylmuramidase (gp61). $\phi J A 1$ and $\phi$ VchO139-I also lack tRNAs-Asn, Ser, Thr, and Pro, found between gp47 and gp48 of N4, but instead both encode a single tRNA-Arg gene as noted above. The location of the tRNA genes is different between these Vibrio phages and N4. 
$\phi J A 1$ and $\phi$ VchO139-I genomes are enriched with selfish DNA compared to N4. Specifically, $\phi J A 1$ and $\phi$ VchO139-I each have an intein within the large terminase protein (JA1_0067) as well as four copies of an $\mathrm{HNH}$ family of homing endonuclease (JA1_0032, 0034, 0041, and 0047 of фJA1 and VCO139_0032, 0034, 0041 and 0047) (Figure 4 and Additional file 1: Table $\mathrm{S} 1$ ), in contrast to N4, which has none of these selfish DNA elements. Homing endonucleases are site-specific DNA endonucleases that initiate mobility by introducing double-strand breaks at defined positions in genomes lacking the endonuclease gene, stimulating repair and recombination pathways that mobilize the endonuclease coding region [34]. These homing endonucleases typically reside within self-splicing group I introns [35]. Indeed, three of the four $\mathrm{HNH}$ endonuclease genes split genes into two parts (N4 homologs gp24, DNAP, and gp43, Figure 4), suggesting that these $\mathrm{HNH}$ homing endonucleases may be carried on an intron.

A virion-associated/secreted lyase enzyme encoded by $\phi J A 1$ has been described [21,22]. We identified a candidate gene, JA1_0065 in $\phi J A 1 ~(87.3 \mathrm{kDa})$ and VCO139_0066 in \$VchO139-I (87.4 kDa), annotated as a putative minor structural protein containing a domain with very weak BLASTP homology to a phagerelated tail fiber protein and a Hidden Markov Model match to a peptidase domain (pfam13884) prototypically found in the endosialidase of bacteriophage $\mathrm{K} 1 \mathrm{~F}$ [36]. The K1F polysialic acid capsule-degrading endosialidase is a key component of the tail spike of phage $\mathrm{K} 1 \mathrm{~F}$, and has been observed in other phages [37]. There are six nucleotide differences between the $\phi J A 1$ and $\phi$ VchO139-I minor structural proteins of which five are non-synonymous changes leading to amino acid differences in the proteins. We speculate that this minor structural protein is the polysaccharide lyase enzyme although verification of this prediction awaits further functional genomics experiments.

\section{N4-like phage family comparisons}

To better understand the diversity and relatedness of the N4 family of phages, genomes with top BLAST matches to N4 and falling under the N4-like phage taxonomic classification in the NCBI database were compared. Using N4 as the reference genome, a total of 18 N4-related phages were compared to N4 with an average percent identity (API) at the amino acid level, as high as $65 \%$ for Enterobacter phage KBNP21 to as low as 43\% for Vibrio phage $\phi J A 1$ (Additional file 1: Table S2). Of the phages compared, the two Vibrio parahaemolyticus phages VBP32 and VBP47 were the closest relatives of фJA1 and $\phi$ VchO139-I with an API to N4 of $44 \%$ (Additional file 1: Table S2). All these genomes showed considerable synteny, but variable gene conservation
(Additional file 1: Figure S4). Every N4-like phage encoded two RNA polymerases, including the vRNAP, making them bona fide members of the N4 family. The presence of $r I I \mathrm{~A}$ and $r I I \mathrm{~B}$ varied widely across the family, as did the gene content between the portal (JA1_0062) and large terminase (JA1_0067) genes. E. coli phage vB_EcoP_G7C had the greatest number of $\mathrm{HNH}$ homing endonuclease genes (5), but none of them appear to have disrupted any gene.

Since the genomes depicted in Additional file 1: Figure S4 were ordered relative to N4 (from most similar to least similar), and only linear relationships can be observed, a dendrogram (splitstree view) based on the mean of the BLASTP score ratio (BSR) was generated (Figure 5 ). This tree shows that there were 3 deep branching subgroups or clades of N4like phages Vibrio and Pseudomonas phages; enteric phages; and Roseovarius, Silicibacter and Sulfitobacter phages.

Initial assemblies using 454 sequence reads revealed the presence of apparent frame-shifts caused by variation in homopolymeric tracts that were subsequently corrected by high-quality Sanger data. We wanted to investigate whether this finding (frame-shifts due to homopolymeric tracts) was unique to these $V$. cholerae phages or prevalent in other phages as well. Using the EMBOSS program fuzznuc, the number of homopolymeric tracts of greater than 5 nucleotides in length were tabulated for the N4 family of phages and for the $E$. coli tailed phages $\lambda, \mathrm{Mu}$, P1, T1, T4, T5 and T7 (Additional file 1: Table S3). This data showed that although homopolymeric tracts of up to 8 nucleotides in length are common in these phages, N4-like phages had the longest homopolymeric tracts among the phages searched (up to 12 nucleotides for $\phi V$ chO139-I). The significance of this finding is not clear at this time, although it may be related to the replication mechanism of the N4-like phages or to the regulation of gene expression via a polymerase slippage mechanism.

\section{$\phi J A 1$ and $\phi$ Vch0139-I employ an N4-like DNA packaging mechanism}

Large terminase protein sequences have been used to construct phylogeny and decipher evolutionary relationships among phages belonging to different families (Casjens et al., 2005). Clustering of the amino acid sequences of the large terminase proteins encoded by $\phi J A 1$ and $\phi$ VchO139-I with that of 109 other phages updated from an earlier study [38], clearly placed both phages within the branch of the N4-like phages (Figure 6). The prototypical N4 phage genome features direct terminal repeats (DTRs), varying in length from 390-440 bps and also contains 3' single-stranded extensions at the ends of the genome [30]. In other N4-like phages for which the DTRs have been determined, the lengths of the DTRs varied from 397 to 1,120 bps (Additional file 1: 


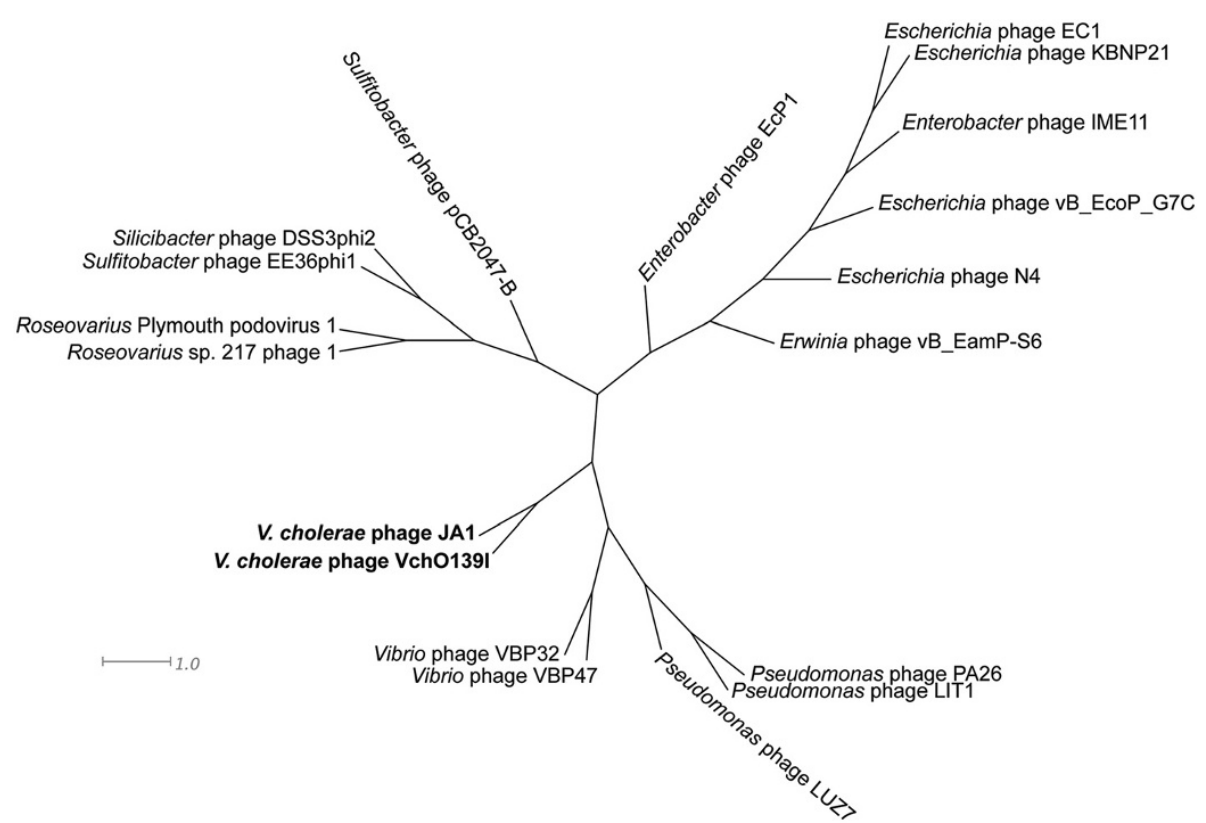

Figure 5 Proteome-based phylogenetic analysis of N4-like phages. A dendrogram was constructed based on the mean of the pairwise BLASTP score ratios (BSRS) of the N4-like group of phages.

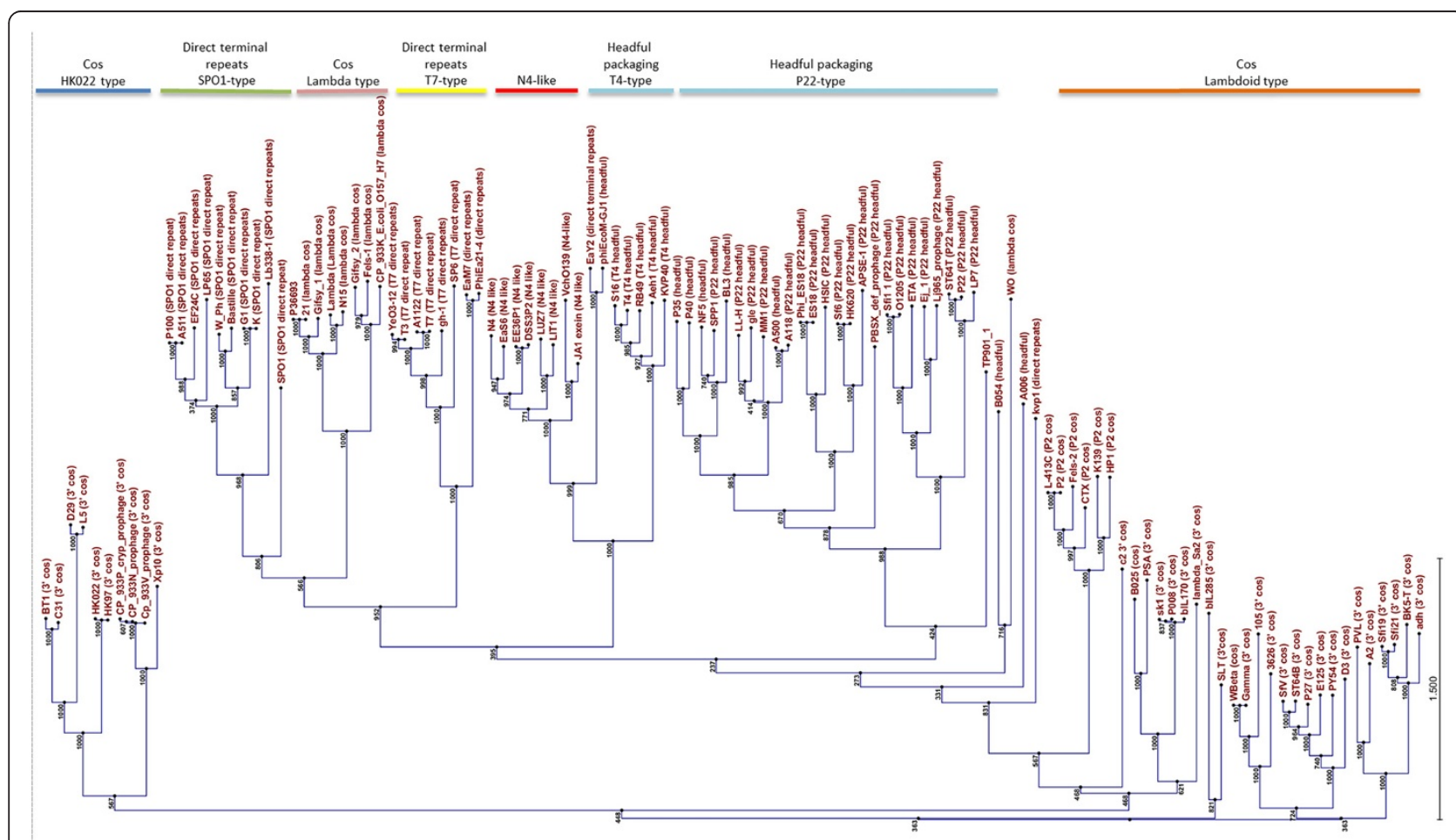

Figure 6 Phylogenetic tree based on the large terminase protein of various phages. ClustalW alignment of 109 large terminase subunit amino acid sequences computed into a phylogenetic tree using Neighbor Joining method and 1000 bootstrap replicates (CLC Genomics Workbench 6). 
Table S3) whereas $\phi J A 1$ and $\phi$ VchO139-I carried by far the longest DTRs of about 1,974 bps.

\section{Conclusions}

Although phages $\phi J A 1$ and $\phi$ VchO139-I are 99\% identical there are considerable differences between them in terms of single nucleotide polymorphisms and some insertions/deletions. Phages can be considered different when there are discernible phenotypic differences (such as plaque morphologies, growth characteristics, host range etc.) that can be linked to genetic differences. In this case, there is a phenotypic difference in the plaque morphology (different sized halos) of $\phi J A 1$ and $\phi$ VchO139-I and hence they would be considered variants although a genetic link has not been established yet. The genetic characterization and genomic data of $\phi J A 1$ and $\phi V$ chO139-I presented in this study lay the foundation for the development of rapid phage-based diagnostics and therapeutics against this cholera-causing $V$. cholerae strain by providing sequence data and gene targets conferring binding specificity and lysis. The genome annotation indicated the absence of any toxin, virulence or lysogeny associated genes that may preclude the phages' therapeutic utility. The gene encoding the secreted lyase enzyme [22] responsible for the different sized halos around the plaques could not definitively be identified from nucleotide differences between the two phages or by strong similarity to other known lyases. The lack of extensive similarity further underscores the remarkable genetic diversity seen in the lyase genes in nature [39]. Further work on identifying the lyase gene using a functional genomic approach is underway. From a phylogenetic perspective, comparison of the genomes of all the currently available N4-like phages has further delineated sub clades within this group of the Podoviridae family.

\section{Methods}

\section{Bacterial strains and culture conditions}

V. cholerae O139 Bengal strain AI1837 or 63-93 (MO45) were used for all phage propagation and large scale preparation of $\phi J A 1$ and $\phi V$ chO139-I lysates. The Shimada serotype collection strains representing serogroups O1 through O206 were used for host range analyses [6]. All strains were grown in $\mathrm{LB}$ or $\mathrm{BHI}$; phage assays were done in LB or BHI or $2 x Y T$ agar plates with the respective soft agar. All the strains were grown from single colonies in the indicated medium (LB or $\mathrm{BHI}$ ) in flasks or tubes at $37^{\circ} \mathrm{C}$ with shaking at $\sim 200 \mathrm{rpm}$.

\section{Phage isolation and propagation}

Untreated raw sewage for phage isolation was collected from the International Centre for Diarrheal Disease Research, Bangladesh (ICDDR,B) hospital sewer located in Dhaka, and filtered through a Whatman filter to remove large particles. Ninety $\mathrm{ml}$ of the filtrate was mixed with
$10 \mathrm{ml}$ of $10 \times \mathrm{LB}$ and $100 \mu \mathrm{l}$ of an overnight culture of $V$. cholerae $\mathrm{O} 139$ strain was added and grown overnight in a $37^{\circ} \mathrm{C}$ shaker. The cultures were spun and filtered through a $0.45 \mu \mathrm{m}$ filter. One hundred $\mu \mathrm{ls}$ of ten-fold serial dilutions of the filtrate were mixed with $100 \mu \mathrm{l}$ of a logarithmic phase culture of $V$. cholerae O139 strain, adsorbed for 20 minutes at $37^{\circ} \mathrm{C}$ and plated with $4 \mathrm{ml}$ of top agar [40]. The plates were incubated overnight at $37^{\circ} \mathrm{C}$.

Single plaques purified from overnight plates were purified twice and then propagated by the confluent lysis method $[40,41]$. The resulting lysate was further purified by $\mathrm{CsCl}_{2}$ gradient centrifugation according to an established protocol [42]. Single step growth experiments were performed as previously described [43,44]. Briefly, host strains were grown to mid-log phase, infected with a multiplicity of infection (MOI) of 10 for $10 \mathrm{~min}$ at $37^{\circ} \mathrm{C}$ in the presence of $1 \mathrm{mM} \mathrm{CaCl}_{2}$. Infected cells were centrifuged and washed three times to remove unbound phage. Infected cells were serially diluted and plated using the soft-agar overlay method. Data presented are the results from two independent experiments.

\section{Phage nomenclature}

In accordance with the recent recommendation for bacterial virus nomenclature, we have named the Vibrio phages as vB_VchP_JA1 and vB_VchP_VchO139-I [40]. In this scheme, the first part of the designation, $\mathrm{vB}$ means 'virus of bacteria', the second part, VchP indicates the bacterial host Vibrio cholerae, and the family of the phage ' $\mathrm{P}$ ' for Podoviridae, and the last part JA1 or VchO139-I indicates the laboratory names. These designations have been used in the title, abstract and GenBank submissions. However, for simplicity, only the laboratory designations $\phi \mathrm{JA} 1$ and $\phi \mathrm{VchO} 139-\mathrm{I}$ are used throughout this manuscript.

\section{Electron microscopy}

Purified phage particles were negatively stained with $2 \%$ uranyl acetate [45]. Samples were observed in a Tecnai $G^{2}$ Spirit electron microscope at $120 \mathrm{kV}$ equipped with an EAGLE CCD camera (FEI Company, Hillsboro, USA). DNA molecules were partially denatured by heating in formamide and prepared for electron microscopy using a modified cytochrome c spreading technique [46]. Electron micrographs of partially denatured molecules along with a size standard (pBluescript plasmid DNA) were measured and processed as described previously [47].

\section{Host-range analysis}

Host range analysis was done by spot tests [48]. The 206 $V$. cholerae serogroup type strains were grown overnight at $37^{\circ} \mathrm{C}$ and $10 \mu \mathrm{l}$ of the overnight cultures were spotted on LB or BHI plates, the spots were allowed to dry, 
followed by spotting $5 \mu \mathrm{l}$ containing $\sim 10^{8}$ PFU total amount of $\phi \mathrm{JA} 1$ or $\phi$ VchO139-I phage lysates. Spot tests were also done on bacterial lawns. In some experiments, either overnight cultures or dilutions thereof, were mixed with phages at different MOI and spotted. The plates were incubated at $37^{\circ} \mathrm{C}$ overnight and the results were scored based on clearing or absence of clearing of bacterial spots. The efficiency of plating (e.o.p) was calculated as the ratio of the titer on a test strain compared to the titer on the strain in which the lysate was prepared. Phages JA1 and VchO139-I were prepared either on AI1837 or 63-93 (MO45). The e.o.p on O139 serogroup strains were 1 whereas in all other serogroup strains the e.o.p was 0 .

\section{Phage DNA extraction and analysis}

Bacteriophage DNA was extracted as described previously $[26,28,42]$. Briefly, phage lysate was treated with DNAse and RNAse and the phage particles were pelleted by highspeed centrifugation. The pellet was resuspended in PBS buffer and phage capsids were lysed by proteinase $\mathrm{K}$ and heat treatment. Phage DNA was extracted by organic solvents, as previously described [42].

\section{Whole genome sequencing of $\phi J \mathrm{~A} 1$ and $\phi$ Vch0139-I}

Shotgun sequencing by the Sanger method was done as follows: Five to ten $\mu \mathrm{g}$ of phage DNA was sheared to $\sim 2 \mathrm{~kb}$ fragments using a nebulizer (Invitrogen corp). The sheared DNA was end polished and cloned into a pCR Blunt 4. Topo Vector. Plasmid DNA was purified from the clones using the Qiagen Plasmid Miniprep kit (Qiagen, Hilden, Germany) and sequenced using an ABI 3700 sequencer with M13 universal and reverse primers. The resulting sequences were assembled using Sequencher software. Gaps in contigs and low coverage regions were filled by primer walking using intact phage DNA as template.

Whole genome pyrosequencing of phages $\phi J A 1$ and $\phi$ VchO139-I was also done in order to boost the coverage of both phage assemblies and to help fill in unclonable regions that may have been toxic to E. coli. The Roche/454 sequencing was done according to the manufacturer's recommended protocol (FLX Titanium) using a Roche/454 sequencer FLX instrument. Subsets of sequences $(15,000)$ were assembled using the Newbler GS De Novo Assembler version 2.6 [49]. The resulting single assembly of each respective genome was used to map the remaining 454 reads and available Sanger reads using the high throughput 'Map Reads to Reference' module in CLC Genomics Workbench version 5.5 (www.clcbio.com) using default settings. Sanger reads were used to manually edit the sequence in homopolymeric regions.

\section{Bioinformatic analyses of sequence data}

The final assembled sequence was annotated using the JCVI annotation pipeline as described previously [50]. Protein molecular weights were determined from predicted coding sequences (CDSs) using the EMBOSS program pepstats. SNPs between the two phage genomes were identified by mapping the $\phi$ VchO139-I 454-reads onto the non-redundant $\phi \mathrm{JA} 1$ genome by first using the high throughput 'Map Reads to Reference' module followed by the 'SNP Detection' module both in CLC Genomics Workbench version 5.5 (www.clcbio.com), using default settings. Homopolymeric tracts were identified by analyzing the underlying sequences for each nucleotide within a tract of six or more A, T, G, or C nucleotides as described previously [51]. SNPs within these homopolymeric tracks were not considered for further analysis. Linear illustrations of multiple phage comparisons were constructed using an in-house (JCVI) PERL script LinearDisplay.pl, showing only pairwise BLASTP results with E-value $\leq 1 \times 10^{-5}$ and percent identity $\geq 35 \%$. Phage phylogenetic trees were constructed using the mean of the BLASTP score ratio as described previously [52]. Comparison of the large terminase protein amino acid sequences was performed as described previously [53] using a dataset modified from the original published set [38]. ClustalW alignments were used to generate a phylogenetic tree with the Neighbor Joining method and 1000 bootstrap replicates.

\section{SDS-PAGE and peptide mass fingerprinting}

Peptide mass fingerprinting was performed as described previously [54,55]. Briefly, purified phage particles were collected by centrifugation and mixed with an equal volume of sample buffer prior to heating at $95^{\circ} \mathrm{C}$ for $5 \mathrm{~min}$. Proteins were separated on precast, horizontal SDS-PAGE gels (Excel Gel gradient 8-18\% PAGE gels, GE Healthcare, Solingen, Germany), followed by staining with Coomassie blue R-350 (Phastblue R; GE Healthcare). Major bands were excised from the gel; the gel pieces were washed twice in $100 \mathrm{mM} \mathrm{NH} \mathrm{HCO}_{3} / 50 \%$ acetonitrile and washed once with $50 \mathrm{ul}$ acetonitrile. Supernatants were discarded and proteins in gel fragments were digested with trypsin at $37^{\circ} \mathrm{C}$ overnight. Supernatants were removed and the gel pieces were extracted twice in $0.1 \%$ TFA $/ 50 \%$ acetonitrile. Supernatants were dried and dissolved in $0.1 \%$ formic acid and analyzed by LC-ESI-MS/MS (Functional Genomics Center, Zurich, Switzerland) and compared against a database of all predicted phage proteins using Scaffold software version 3 (Proteome Software Inc., Portland, OR, USA). Protein domains were predicted with InterProScan (http://www. ebi.ac.uk/InterProScan). 


\section{Determination of the structure of genomic ends}

The physical genome structure (linear vs circular) of $\phi J A 1$ and $\phi$ VchO139-I was assessed by restriction digestion profiles under conditions recommended by the manufacturers (New England Biolabs, Ipswich, MA and Fermentas-Thermo Scientific, Waltham, MA). Bal31nuclease digestion was performed as previously described [26]. The presence of putative cohesive genomic ends was evaluated by digesting genomic DNA with ClaI, Van91I and OliI, heating half of the digest to $75^{\circ} \mathrm{C}$ for $10 \mathrm{~min}$ and comparing it to the non-heated restriction digests after electrophoresis in an agarose gel. Pulsed-field gel electrophoresis was done using a CHEFDR-III apparatus (BioRad, Hercules, CA) under the following conditions: Gels (1\%) were cast using Megabase agarose (BioRad) and run at $14^{\circ} \mathrm{C}$ buffer temperature with 1-25 s switch time, $6 \mathrm{~V} / \mathrm{cm}$ and $120^{\circ}$ angle for 17.5 h. PFGE MidRange Marker I and II (New England Biolabs, Ipswich, MA) were used for estimating fragment sizes. Primers for genome-end runoff sequencing were designed based on the consensus genome sequence and Sanger sequencing reactions were carried out using either intact $\phi J A 1$ DNA or isolated restriction fragments as templates. The resulting sequence reads were manually verified by Sequiserve $\mathrm{GmbH}$, Vaterstetten, Germany. Sequencing reactions were performed at the highest possible annealing temperatures in order to prevent potential re-circularization of the template DNA molecule. Phage фJA1 genome-end fragments resulting from restriction digestion with SalI or NruI restriction enzyme were cut out of agarose gels and extracted using QiaQuick Gel Extraction Kit (Qiagen, Hilden, Germany). Isolated fragments were checked for purity by electrophoresis and used as templates for Sanger sequencing.

\section{Nucleotide sequence accession numbers}

Complete nucleotide sequences of $\phi J A 1$ and $\phi$ VchO139-I were deposited to GenBank under accession numbers KC438282 and KC438283 respectively. The following seventeen N4-like phage genomes were obtained from NCBI for use in whole genome comparisons: 1) E. coli phage KBNP21, JX415535 [56]; 2) E. coli phage N4, EF056009 (unpublished); 3) E. coli phage vB_EcoP_G7, HQ259105 [57]; 4) Enterobacter phage EcP1, HQ641380 (unpublished); 5) E. coli phage IME11, JX880034 [58]; 6) Erwinia phage vB_EamP-S6, HQ728266 [33] 7) Pseudomonas phage LIT1, FN422399; 8) Pseudomonas phage LUZ7, FN422398 [59]; 9) Roseovarius sp. 217 phage 1, FR682616 (unpublished); 10) Silicibacter phage DSS3phi2, FJ591093 and 11) Sulfitobacter phage EE36phi1, FJ591094 [60]; 12) Roseovarius Plymouth Podovirus 1, FR719956; 13) Pseudomonas phage PA26, JX194238 [59]; 14) Vibrio phage VBP32, HQ634196 (unpublished); 15) Vibrio phage
VBP47, HQ634194 (unpublished); 16) Sulfitobacter phage pCB2047-B, HQ317387 (unpublished) and 17) E. coli phage EC1, KC206276 (unpublished).

\section{Additional file}

\begin{abstract}
Additional file 1: Figure S1. Host range analysis of phage Vch0139by spot test. Ninety-six bacterial cultures of different $V$. cholerae strains were mixed with $\phi V$ chO139-I and spotted using a sterile 96 pronged stainless steel replicator. Plate on the left shows the spots of cultures with buffer and on the right shows the spots of cultures mixed with phage. Complete lysis of the $\mathrm{V}$. cholerae strain 0139 spot by phage VchO139-I is indicated by an underline in the image whereas all other spots show normal growth in the presence of phage. Figure S2A. Determination of the size, linearity and variability of the genomes of phages $\phi J A 1$ and $\phi V$ chO139-I. Pulse field gel electrophoresis of uncut genomic DNAs of phages $\phi J A 1$ (c) and фVChO139-I (d). a and b: NEB Mid-Range PFG markers I and II. Approximate band sizes are indicated. In e) the number of fragments produced by double digestion of $\phi J A 1$ DNA with two restriction enzymes are shown; lane 1: Uncut JA1; lane 2: JA1 (Xho-Pst); lane 3: JA1 (Xhol-Sall). Figure S2B. Restriction fragment length polymorphism analysis of $\phi J A 1$ and $\phi V$ ch0139-I DNAs. Genomic DNAs of phages $\phi J A 1$ and $\phi V$ chO139-I were digested with the indicated enzymes and run on an agarose gel. The restriction patterns generated by EcoRl and HindIII are identical whereas that of Hpall and Xmnl show some differences. Figure S3. Pile-up of sequence reads at the $3^{\prime}$ end of the non-redundant genome assembly. Sanger sequencing based $\phi J A 1$ assembly was used as the reference for mapping the 454 sequence reads. The depth of coverage (approx. 3500-fold) of around 1974 bases at the $3^{\prime}$ end is represented two fold more than the rest of the genome (1800-fold) as is evident by the sharp increase in coverage at this location marked by the arrow. Figure S4. Genome maps and protein identity comparison between N4-like phages. Physical map of the genomes of the N4-like phages. The linear map is based on nucleotide sequences of the phage genomes and predicted open reading frames. CDSs are labeled by locus identifier and colored by functional role categories as noted in the boxed key. BLASTP matches between CDSs are colored by protein percent identity (see key). Genomes are ordered from most to least similar to bacteriophage N4. Table S1. Comparison of bacteriophages $\phi J A 1$ and $\phi V$ ChO139-I. Table S2. Average Percent Identity of N4-like Phages at the Amino Acid Level. Table S3. Comparison of Miscellaneous features between N4-like Phages and Coliphages.
\end{abstract}

\section{Competing interests}

The authors declare that they have no competing interests.

\section{Authors' contributions}

SS, and MJA conceived the project; SS, MJA, MJL, DEF, JK and RC designed experiments; SS, RC, MR, JK, MH, and BB performed experiments; SS and ML did Shotgun cloning and Sanger sequencing; KABL, KMW and AB did 454 sequencing; DEF, KABL, JK and SS did post sequence analysis; SS, JK, DEF wrote the manuscript and KABL and MJA edited the manuscript. All authors read and approved the final manuscript.

\section{Acknowledgements}

MR was supported by Morgan State University Office of Faculty Professional Development under Title III Grant from the US Department of Education and MSU NIH-EARDA Grant from NICHD. The work done at NMRC was supported by the Transformational Medical Technologies Program under contract TMTIIB06RSQ002 through the Defense Threat Reduction Agency to SS. The authors would like to thank Dr. Rudi Lurz (Max-Planck-Institute for Molecular Genetics; Berlin, Germany) for help with electron microscopy work and Ms. Kristin Kittle for editorial assistance The views expressed in this article are those of the authors and do not necessarily reflect the official policy or position of the Department of the Navy or the Critical Reagents Program of the Chemical Biological Medical Systems, Joint Program Executive office, Department of Defense, nor the U.S. Government. The BDRD, NMRC authors are employees of the U.S. Government. This work was prepared as part of 
their official duties. Title 17 U.S.C. \$105 provides that "Copyright protection under this title is not available for any work of the United States Government." Title 17 U.S.C. §101 defines a U.S. Government work as a work prepared by a military service member or employee of the U.S. Government as part of that person's official duties.

\section{Author details}

1J Craig Venter Institute, Rockville, MD, USA. ${ }^{2}$ Institute of Food, Nutrition and Health, ETH Zurich, Schmelzbergstrasse 7, 8092, Zurich, Switzerland. ${ }^{3}$ Henry M. Jackson Foundation, Bethesda, MD, USA. ${ }^{4}$ Biological Defense Research Directorate, Naval Medical Research Center, Ft. Detrick, MD, USA.

${ }^{5}$ Department of Biology/Medical Technology, School of Computer, Mathematical and Natural Sciences, Morgan State University, 1700 E. Cold Spring Lane, Baltimore, MD, USA. Intralytix, Inc., The Columbus Center, $701 \mathrm{E}$. Pratt St, Baltimore, MD, USA. 'Department of Microbiology, Faculty of Medicine, Kuwait University, Safat, Kuwait. ${ }^{8}$ Department of Molecular and Cell Biology, University of California Berkeley, Berkeley, CA, USA. ${ }^{9}$ Current address: GoldBelt Raven, LLC, Frederick, MD 21701, USA

Received: 4 February 2013 Accepted: 21 May 2013

Published: 28 May 2013

\section{References}

1. Centers for Disease Control and Prevention: Update: outbreak of cholera --Haiti, 2010. MMWR Morb Mortal Wkly Rep 2010, 59:1586-1590.

2. Farmer P, Almazor CP, Bahnsen ET, Barry D, Bazile J, Bloom BR, Bose N, Brewer T, Calderwood SB, Clemens JD, et al: Meeting cholera's challenge to Haiti and the world: a joint statement on cholera prevention and care. PLoS Negl Trop Dis 2011, 5:e1145.

3. Centers for Disease Control and Prevention: Update on cholera -- Haiti, Dominican Republic, and Florida. MMWR Morb Mortal Wkly Rep 2010, 59:1637-1641

4. WHO: Cholera fact sheet:; 2011. http://www.who.int/mediacentre/factsheets/ fs107/en/

5. WHO: Cholera. Weekly Epidemiological Record 2011, 87:289-304

6. Shimada T, Arakawa E, Itoh K, Okitsu T, Matsushima A, Asai Y, Yamai S, Nakazato T, Nair GB, Albert MJ, Takeda Y: Extended serotyping scheme for Vibrio cholerae. Curr Microbiol 1994, 28:175-178

7. Mukhopadhyay AK, Ramamurthy T: Asiatic cholera: mole hills and mountains. In Epidemiological and molecular aspects of cholera. Edited by Ramamurthy T, Bahattacharya SK. New York: Springer; 2011:5-29.

8. Ramamurthy T, Garg S, Sharma R, Bhattacharya SK, Nair GB, Shimada T, Takeda T, Karasawa T, Kurazano H, Pal A, et al: Emergence of novel strain of Vibrio cholerae with epidemic potential in southern and eastern India. Lancet 1993, 341:703-704.

9. Stroeher UH, Manning PA: Vibrio cholerae serotype 0139: swapping genes for surface polysaccharide biosynthesis. Trends Microbiol 1997, 5:178-180

10. Sozhamannan S, Yildiz FH: Diversity and genetic basis of polysaccharide biosynthesis in Vibrio cholerae. In Epidemiological and molecular aspects of cholera. Edited by Ramamurthy T, Bahattacharya SK. New York: Springer; 2011:120-160

11. Faruque SM, Albert MJ, Mekalanos JJ: Epidemiology, genetics, and ecology of toxigenic Vibrio cholerae. Microbiol Mol Biol Rev 1998, 62:1301-1314.

12. Mekalanos JJ, et al: The evolution of Vibrio cholerae as a pathogen. In Epidemiology and molecular aspects of Cholera. Edited by Ramamurthy T, Ramamurthy T, Bahattacharya SK. New York: Springer; 2011:97-115.

13. Waldor MK, Mekalanos JJ: Lysogenic conversion by a filamentous phage encoding cholera toxin. Science 1996, 272:1910-1914.

14. Engel HW, Berwald LG, Grange JM, Kubin M: Phage typing of mycobacterium kansasii. Tubercle 1980, 61:11-19.

15. Loessner MJ: Improved procedure for bacteriophage typing of Listeria strains and evaluation of new phages. Appl Environ Microbiol 1991, 57:882-884

16. Ward $L R$, de Sa JD, Rowe B: A phage-typing scheme for Salmonella enteritidis. Epidemiol Infect 1987, 99:291-294.

17. Chattopadhyay DJ, Sarkar BL, Ansari MQ, Chakrabarti BK, Roy MK, Ghosh AN, Pal SC: New phage typing scheme for Vibrio cholerae 01 biotype El Tor strains. J Clin Microbiol 1993, 31:1579-1585.

18. Mukerjee S, Roy UK, Rudra BC: Studies on typing of cholera vibrios by bacteriophage. V. Geographical distribution of phage-types of Vibrio cholerae. Ann Biochem Exp Med 1963, 23:523-530.
19. Albert MJ, Bhuiyan NA, Rahman A, Ghosh AN, Hultenby K, Weintraub A, Nahar S, Kibriya AK, Ansaruzzaman M, Shimada T: Phage specific for Vibrio cholerae 0139 Bengal. J Clin Microbiol 1996, 34:1843-1845.

20. Chakrabarti AK, Ghosh AN, Nair GB, Niyogi SK, Bhattacharya SK, Sarkar BL: Development and evaluation of a phage typing scheme for Vibrio cholerae 0139. J Clin Microbiol 2000, 38:44-49.

21. Linnerborg M, Weintraub A, Albert MJ, Widmalm G: Depolymerization of the capsular polysaccharide from Vibrio cholerae 0139 by a lyase associated with the bacteriophage JA1. Carbohydr Res 2001, 333:263-269.

22. Adeyeye J, Azurmendi HF, Stroop CJ, Sozhamannan S, Williams AL, Adetumbi AM, Johnson JA, Bush CA: Conformation of the hexasaccharide repeating subunit from the Vibrio cholerae 0139 capsular polysaccharide. Biochemistry 2003, 42:3979-3988.

23. Ackermann HW: Bacteriophage observations and evolution. Res Microbio 2003, 154:245-251

24. Ackermann HW: 5500 Phages examined in the electron microscope Arch Virol 2007, 152:227-243.

25. Falco SC, Zehring W, Rothman-Denes LB: DNA-dependent RNA polymerase from bacteriophage N4 virions. Purification and characterization. J Biol Chem 1980, 255:4339-4347.

26. Klumpp J, Dorscht J, Lurz R, Bielmann R, Wieland M, Zimmer M, Calendar R, Loessner MJ: The terminally redundant, nonpermuted genome of Listeria bacteriophage A511: a model for the SPO1-like myoviruses of Grampositive bacteria. J Bacterio/ 2008, 190:5753-5765.

27. Born Y, Fieseler L, Marazzi J, Lurz R, Duffy B, Loessner MJ: Novel virulent and broad-host-range Erwinia amylovora bacteriophages reveal a high degree of mosaicism and a relationship to Enterobacteriaceae phages. Appl Environ Microbiol 2011, 77:5945-5954.

28. Klumpp J, Fouts DE, Sozhamannan S: Next-generation sequencing technologies and the changing landscape of phage genomics. Bacteriophage 2012, 2:190-199.

29. Kilcher S, Loessner MJ, Klumpp J: Brochothrix thermosphacto bacteriophages feature heterogeneous and highly mosaic genomes and utilize unique prophage insertion sites. J Bacterio/ 2010, 192:5441-5453.

30. Ohmori H, Haynes LL, Rothman-Denes LB: Structure of the ends of the coliphage N4 genome. J Mol Biol 1988, 202:1-10.

31. Willis SH, Kazmierczak KM, Carter RH, Rothman-Denes LB: N4 RNA polymerase II, a heterodimeric RNA polymerase with homology to the single-subunit family of RNA polymerases. J Bacteriol 2002, 184:4952-4961.

32. Paddison P, Abedon ST, Dressman HK, Gailbreath K, Tracy J, Mosser E, Neitzel J, Guttman B, Kutter E: The roles of the bacteriophage T4 $r$ genes in lysis inhibition and fine-structure genetics: a new perspective. Genetics 1998, 148:1539-1550.

33. Abedon ST: Bacteriophage T4 resistance to lysis-inhibition collapse. Genetical research 1999, 74:1-11.

34. Edgell DR, Gibb EA, Belfort M: Mobile DNA elements in T4 and related phages. Virol J 2010, 7:290.

35. Stoddard BL: Homing endonuclease structure and function. Quart rev biophys 2005, 38:49-95.

36. Stummeyer K, Dickmanns A, Muhlenhoff M, Gerardy-Schahn R, Ficner R: Crystal structure of the polysialic acid-degrading endosialidase of bacteriophage K1F. Nat struct mol biol 2005, 12:90-96.

37. Stummeyer K, Schwarzer D, Claus H, Vogel U, Gerardy-Schahn R, Muhlenhoff M: Evolution of bacteriophages infecting encapsulated bacteria: lessons from Escherichia coli K1-specific phages. Mol Microbiol 2006, 60:1123-1135.

38. Casjens SR, Gilcrease EB, Winn-Stapley DA, Schicklmaier P, Schmieger H, Pedulla ML, Ford ME, Houtz JM, Hatfull GF, Hendrix RW: The generalized transducing Salmonella bacteriophage ES18: complete genome sequence and DNA packaging strategy. I Bacteriol 2005, 187:1091-1104.

39. Lombard V, Bernard T, Rancurel C, Brumer H, Coutinho PM, Henrissat B: A hierarchical classification of polysaccharide lyases for glycogenomics. Biochem J 2010, 432:437-444

40. Kropinski AM, Mazzocco A, Waddell TE, Lingohr E, Johnson RP: Enumeration of bacteriophages by double agar overlay plaque assay. Methods Mol Biol 2009, 501:69-76.

41. Adams MH: Methods of study of bacterial viruses. In Bacteriophages. New York: Interscience publishers, Inc; 1959:443-457.

42. Sambrook J, Russell DW: Molecular cloning - a laboratory manual. 3rd edition. New York: Cold Spring Harbor Laboratory Press; 2001.

43. Hyman $\mathrm{P}$, Abedon ST: Practical methods for determining phage growth parameters. Methods Mol Biol 2009, 501:175-202. 
44. Mathews CK, Kutter EM, Mosig G, Berget PB: Bacteriophage T4. Washington, DC: American Society for Microbiology; 1983.

45. Steven AC, Trus BL, Maizel JV, Unser M, Parry DA, Wall JS, Hainfeld JF, Studier FW: Molecular substructure of a viral receptor-recognition protein. The gp17 tail-fiber of bacteriophage T7. J Mol Biol 1988, 200:351-365.

46. Inman RB, Schnos M: Partial denaturation of thymine- and 5-bromouracil -containing lambda DNA in alkali. J Mol Biol 1970, 49:93-98.

47. Littlewood RK, Inman RB: Computer-assisted DNA length measurements from electron micrographs with special reference to partial denaturation mapping. Nucleic Acids Res 1982, 10:1691-1706.

48. Mazzocco A, Waddell TE, Lingohr E, Johnson RP: Enumeration of bacteriophages using the small drop plaque assay system. Methods $\mathrm{Mol}$ Biol 2009, 501:81-85.

49. Margulies M, Egholm M, Altman WE, Attiya S, Bader JS, Bemben LA, Berka J, Braverman MS, Chen YJ, Chen Z, et al: Genome sequencing in microfabricated high-density picolitre reactors. Nature 2005, 437:376-380.

50. Stevens RH, Ektefaie MR, Fouts DE: The annotated complete DNA sequence of Enterococcus faecalis bacteriophage phiEf11 and its comparison with all available phage and predicted prophage genomes. FEMS Microbiol Lett 2011, 317:9-26.

51. Fouts DE, Mongodin EF, Mandrell RE, Miller WG, Rasko DA, Ravel J, Brinkac LM, DeBoy RT, Parker CT, Daugherty SC, et al: Major structural differences and novel potential virulence mechanisms from the genomes of multiple Campylobacter species. PLoS Biol 2005, 3:e15.

52. Fouts DE: Phage_Finder: automated identification and classification of prophage regions in complete bacterial genome sequences. Nucleic Acids Res 2006, 34:5839-5851.

53. Dorscht J, Klumpp J, Bielmann R, Schmelcher M, Born Y, Zimmer M, Calendar R, Loessner MJ: Comparative genome analysis of Listeria bacteriophages reveals extensive mosaicism, programmed translational frameshifting, and a novel prophage insertion site. J Bacterio/ 2009, 191:7206-7215

54. Zimmer M, Sattelberger E, Inman RB, Calendar R, Loessner MJ: Genome and proteome of Listeria monocytogenes phage PSA: an unusual case for programmed +1 translational frameshifting in structural protein synthesis. Mol Microbiol 2003, 50:303-317.

55. Zimmer M, Scherer S, Loessner MJ: Genomic analysis of Clostridium perfringens bacteriophage phi3626, which integrates into guaA and possibly affects sporulation. J Bacterio/ 2002, 184:4359-4368.

56. Nho SW, Ha MA, Kim KS, Kim TH, Jang HB, Cha IS, Park SB, Kim YK, Jung TS: Complete genome sequence of the bacteriophages ECBP1 and ECBP2 isolated from Two different Escherichia coli strains. J Virol 2012, 86:12439-12440.

57. Kulikov E, Kropinski AM, Golomidova A, Lingohr E, Govorun V, Serebryakova M, Prokhorov N, Letarova M, Manykin A, Strotskaya A, Letarov A: Isolation and characterization of a novel indigenous intestinal N4-related coliphage vB_EcoP_G7C. Virology 2012, 426:93-99.

58. Fan H, An X, Huang Y, Zhang Z, Mi Z, Tong Y: Complete genome sequence of IME11, a New N4-like bacteriophage. J Virol 2012, 86:13861.

59. Ceyssens PJ, Brabban A, Rogge L, Lewis MS, Pickard D, Goulding D, Dougan G, Noben JP, Kropinski A, Kutter E, Lavigne R: Molecular and physiological analysis of three Pseudomonas aeruginosa phages belonging to the "N4-like viruses". Virology 2010, 405:26-30.

60. Zhao Y, Wang K, Jiao N, Chen F: Genome sequences of two novel phages infecting marine Roseobacters. Environ Microbiol 2009, 11:2055-2064.

doi:10.1186/1743-422X-10-165

Cite this article as: Fouts et al:: Whole genome sequencing and comparative genomic analyses of two Vibrio cholerae 0139 Bengalspecific Podoviruses to other N4-like phages reveal extensive genetic diversity. Virology Journal 2013 10:165.

\section{Submit your next manuscript to BioMed Central and take full advantage of:}

- Convenient online submission

- Thorough peer review

- No space constraints or color figure charges

- Immediate publication on acceptance

- Inclusion in PubMed, CAS, Scopus and Google Scholar

- Research which is freely available for redistribution

Submit your manuscript at www.biomedcentral.com/submit 